\title{
FÓRUM
}

Submetido em 22.09.2016. Aprovado em 14.03.2017

Avaliado pelo processo de double blind Review. Editores Científicos: Marlei Pozzebon, Eduardo Henrique Diniz, Nathalie Mitev, François-Xavier de Vaujany, Miguel Pina e Cunha e Bernard Leca

DOI: http://dx.doi.org/10.1590/So034-759020170605

\section{PERCEPÇÃO SOBRE A SOCIOMATERIALIDADE DAS PRÁTICAS DE CONTABILIDADE GERENCIAL}

\author{
Perceptions about the sociomateriality of management accounting practices \\ Percepción acerca de la sociomaterialidad de las prácticas de contabilidad de gestión
}

\begin{abstract}
RESUMO
No contexto de gestão organizacional e visando o aprofundamento do conhecimento no campo da Contabilidade Gerencial, esta pesquisa propôs um constructo que contribui com a compreensão sobre a percepção dos gestores sobre a sociomaterialidade de práticas de contabilidade gerencial (PCG) com base na lógica institucional cerimonial (uso baseado em ritos) versus a instrumental (uso baseado na resolução de problemas) valendo-se da Nova Sociologia Institucional (NIS) e das digressões de Bush $(1983,1987)$. Por meio de um levantamento em 102 organizações não financeiras de grande porte que operam no Brasil, identificou-se que, dependendo do arranjo de forças isomórficas e de difusão a que as PCG estão submetidas, elas são levadas a assumir comportamentos cerimonial (5\%), instrumental (61\%) ou misto (26\%). Pode-se inferir que nessas organizações as PCG estão sendo usadas prioritariamente como tecnologias para a resolução de problemas e contribuem com alteração do contexto onde estão inseridas.
\end{abstract}

PALAVRAS-CHAVE | Teoria institucional, práticas de contabilidade gerencial, sociomaterialidade, cerimonialidade, instrumentalidade.

\section{ABSTRACT}

Our research, conducted in the context of organizational management in Brazil, aimed at deepening the knowledge in the Managerial Accounting field. The purpose was to propose a construct that contributes to understanding managers' perceptions of the sociomateriality of management accounting practices (práticas de contabilidade gerencial, MAP) based on the ceremonial (rites-based) versus instrumental (problem solving) institutional logic, drawing on New Institutional Sociology and on Bush's digressions $(1983,1987)$. Through a survey of 102 large non-financial organizations operating in Brazil, we identified that depending on the arrangement between isomorphic forces and diffusion to which the PCGs are subjected, they assume ceremonial (5\%), instrumental (61\%), or mixed (26\%) behavioral characteristics. We infer that in these organizations, PCGs are primarily being used as problem solving techniques and contribute to changing the context in which they are applied.

KEYWORDS I Institutional theory, management accounting practices, sociomateriality, ceremoniality, instrumentality.

\section{RESUMEN}

En el contexto de la gestión organizacional y con el objetivo de profundizar el conocimiento en el campo de la contabilidad de gestión, esta investigación propone un constructo que contribuye a la comprensión de la percepción de los gestores acerca de la sociomaterialidad de las prácticas de contabilidad de ges tión (PCG) con base en la lógica institucional ceremonial (uso basado en ritos) frente a la instrumental (uso basado en resolución de problemas) valiéndose de la Nueva Sociología Institucional (NIS) y de las digresiones de Bush $(1983,1987)$. A través de un relevamiento realizado en 102 grandes organizaciones no financieras que operan en Brasil, se identificó que dependiendo de la disposición de las fuerzas isomórficas y de difusión a que están sometidas las PCG, estas tienen que asumir un comportamiento ceremonial (5\%), instrumental (61\%) o mixto (26\%). Se puede inferir que en dichas organizaciones las PCG se utilizan, prioritariamente, como tecnologías para la resolución de problemas, y, por consiguiente, contribuyen a cambiar el contexto en el que están insertadas.

PALABRAS CLAVE / Teoría institucional, prácticas de contabilidad de gestión, sociomaterialidad, ceremonialidad, instrumentalidad. Professor da Faculdade FIPECAFI São Paulo - SP, Brasil

reiguerr@usp.br

Professor da Universidade de São

Paulo, Faculdade de Economia

Administração e Contabilidade -

São Paulo - SP, Brasil 


\section{INTRODUÇÃO}

Na busca pela melhoria de desempenho, as organizações se valem de artefatos caracterizados pela Contabilidade Gerencial “como modelos de gestão, sistemas de gestão, sistemas de informação e conceitos de avaliação de desempenho que possam ser utilizados por profissionais da Contabilidade Gerencial no exercício de suas funções" (Guerreiro, Cornachione, \& Soutes, 2011, p. 90), tais como o orçamento empresarial (budget), o custeio ABC e o Balanced Scorecard (BSC). A pesquisa desses artefatos tem se destacado sob a perspectiva de entendê-los como práticas de Contabilidade Gerencial (Beuren, Rengel, \& Rodrigues Junior, 2015; Davila, 2000; Frezatti, Barroso, \& Carter, 2015; Frezatti, Relvas, \& Junqueira, 2010; Otley, 1978; Tuomela, 2005).

A abordagem econômica racional da Teoria Neoclássica vem sendo questionada por diversos autores, como Scapens (1994), Burns e Scapens (2000), e Guerreiro, Frezatti, Lopes, e Pereira (2005). Machado-da-Silva, Silva, e Crubellate (2005) entendem que, diferentemente da Teoria Econômica Neoclássica, a Teoria Institucional pode contribuir para a compreensão das Práticas de Contabilidade Gerencial (PCG). Por meio da Teoria Institucional, é possível estudar as PCG como instituições que surgem em decorrência de sua participação na práxis diária das organizações, uma vez que elas desempenham papéis nos contextos sociais em que estão inseridas, contribuindo para que decisões, e consequentemente mudanças sociais, ocorram (Seo \& Creed, 2002). Elas também podem ser consideradas tecnologias utilizadas como suporte ao processo de gestão (Adler \& Borys, 1996; Ahrens \& Chapman, 2004; Scapens, 1994; Seo \& Creed, 2002; Soeiro, Miranda, \& Araújo, 2016).

A Teoria Institucional é muito ampla, sendo classificada diferentemente por diversos autores. Este trabalho, pelo fato de estar relacionado com a Contabilidade Gerencial, se valerá da classificação adotada por Burnes e Scapens (2000), que a classifica em três diferentes vertentes: Nova Economia Institucional (New Institutional Economics [NIE]), que tem o foco nas macroinstituições e estuda os relacionamentos entre organizações e o ambiente em que estão inseridas, e se vale de trabalhos tais como os de Coase (1937) e Williamson (1971); Velha Economia Institucional (Old Institutional Economics [OIE]), que estuda o microprocesso de institucionalização (hábitos que se transformam em rotinas e estas, por sua vez, em instituições) e se vale de trabalhos tais como os de Barley e Tolbert (1997) e Burns e Scapens (2000); e a Nova Sociologia Institucional (New Institutional Sociology [NIS]), que se concentra, predominantemente, em analisar os efeitos de instituições extraorganizacionais (sociais, econômicas e políticas) em práticas contábeis das organizações (Burns \& Scapens, 2000) e se vale de trabalhos como os de Meyer e Rowan (1977), DiMaggio e Powell (1983), Tolbert e Zucker (1983) e Friedland e Alford (1991).

A Teoria Institucional possibilita compreender as PCG como instituições, que surgem em decorrência da necessidade humana de conseguir estabilidade, em meio às incertezas e constantes mudanças que ocorrem nos contextos sociais, em função das diferentes lógicas e racionalidades institucionais (Burns \& Scapens, 2000; Scapens, 1994; Seo \& Creed, 2002; Soeiro et al., 2016). Elas interagem umas com as outras e com os atores organizacionais, e atuam sobre os ambientes em que estão inseridas, sendo também influenciadas por eles, contribuindo para o processo de mudança da realidade social. Tensões que desencadeiam o processo de mudança podem vir tanto de dentro como de fora das organizações (Scott, 2001). Um conjunto dinâmico de forças advindas de diferentes contextos pode surgir, contribuindo para que PCG sejam institucionalizadas ou desinstitucionalizadas (Tolbert \& Zucker, 1999).

No entendimento de Aguiar e Guerreiro (2008), as tensões internas surgem nas organizações em decorrência da necessidade de adaptar soluções específicas, que se estendem ao longo do tempo, do desalinhamento entre estruturas normativas, cognitivas e regulativas, e de diferentes interpretações advindas de diferentes esquemas cognitivos. Neste trabalho, considera-se que estrutura formal é a manifestação de poderosas regras institucionais que funcionam como mitos altamente racionalizados e que são obrigatórios em determinadas organizações, tais como: posições funcionais, políticas, programas, procedimentos etc. (Meyer \& Rowan, 1977).

Na visão institucionalista, as tensões que caracterizam o ambiente da firma podem ser expressas e percebidas por meio de diversas dicotomias, tais como: formal versus informal, revolucionária versus evolutiva, regressiva versus progressiva, e cerimonial versus instrumental (Machado-da-Silva et al., 2005). As dicotomias também têm sido chamadas pelos pesquisadores de dualidades (Jones, Boxenbaum, \& Anthony, 2013). Entre as contradições institucionais percebidas, pode-se considerar o fato de que as práticas devem ser entendidas, simultaneamente, como materiais e simbólicas (Friedland \& Alford, 1991; Jones et al., 2013).

As lógicas institucionais são socialmente construídas valendo-se de padrões históricos, de símbolos culturais e práticas materiais, pressuposições, valores e crenças, pelos quais indivíduos produzem e reproduzem suas substâncias materiais, organizam tempo e espaço, e proveem sentido para suas atividades diárias (Raey \& Jones, 2015). Elas proveem, ainda, 
uma conexão entre a ação e as instituições, o que possibilita compreender as possíveis conexões existentes entre macro e microdimensões que estão associadas aos comportamentos das instituições (Thornton \& Ocasio, 2008)

Material e simbólico estão imbricados, sendo que um afeta e é afetado pelo outro; as lógicas são contextuais e transmitidas por membros em sua percepção de tempo e espaço, como se fosse transmitida uma teoria advinda de sua cultura com base em seus padrões de interpretação de símbolos, crenças e práticas (Jones et al., 2013). Pode-se considerar que as PCG, quando associadas com as lógicas institucionais, por meio da racionalidade, passam a ser providas de uma sociomaterialidade, ou seja, a forma pela qual tais instituições interagem com a realidade social passa a ser notada, e, por meio da linguagem, é possível expressar o entendimento de como são percebidas pelos atores organizacionais.

Thornton, Ocasio, e Lounsbury (2012) definem duas dimensões das instituições: quanto aos seus aspectos materiais, estão associadas com a estrutura e as práticas; e, quanto aos aspectos simbólicos, estão associadas com a idealização e o significado.

Valendo-se da abordagem proporcionada pela NIS, as PCG podem ser observadas por sua sociomaterialidade, a qual decorre do emaranhamento constitutivo entre o social e o material no dia a dia da vida organizacional da qual fazem parte, e que permite explicitar, por meio da linguagem, o seu entendimento (Orlikowski, 2007). As sociomaterialidades, concretamente, fundamentam ou comunicam certas estruturas e práticas, vistas como implícitas ou periféricas em muitos estudos de lógicas institucionais (Friedland, 2013; Friedland \& Alford, 1991; Smets \& Jarzakowski, 2013).

Sua invisibilidade natural torna-as difíceis de serem examinadas, e, em consequência, poucos estudos têm sido feitos sobre sua natureza; entretanto, se materiais, podem exercer papéis como âncoras ou mesmo catalisadores nos processos de mudanças organizacionais, impactando não somente as práticas e as estruturas, mas também os símbolos e as ideias (Jones et al., 2013). Dessa forma, a fim de examinar a sociomaterialidade das PCG em seus contextos organizacionais, parte-se da premissa de que a identificação das lógicas institucionais associadas aos seus usos pode servir como proxy de uma dimensão linguística, para expressar como é percebida a sua sociomaterialidade.

As organizações adotam PCG por sua ampla aceitação social, mesmo que elas possam se evidenciar, posteriormente, como aberrações quando comparadas aos cumprimentos dos objetivos aos quais estavam orginalmente associadas (Hall \& Taylor, 2003). Nas palavras de Hall e Taylor (2003) “Campbel exprime bem esse modo de ver as coisas ao falar de uma 'lógica das conveniências sociais’ por oposição a uma ‘lógica instrumental'” (p. 211). Assim, nesta pesquisa, assume-se que a dicotomia cerimonial versus instrumental (Bush, 1983) pode contribuir para o entendimento sobre a percepção da sociomaterialidade das práticas usadas em Contabilidade Gerencial e possibilita compreender o papel dessas práticas em um continuum organizacional que permite que elas sejam percebidas, idealmente, desde uma condição de totalmente materiais (instrumentalidade) até totalmente simbólicas (cerimonialidade). Dessa forma, é possível compreender, por exemplo, por que uma mesma prática - tal como o orçamento empresarial - pode oferecer diferentes níveis de benefícios de uso, em diferentes organizações e/ou contextos, possibilitando, assim, por meio da compreensão de sua sociomaterialidade, obter-se o máximo benefício no uso das PCG, seja ele de que natureza for.

Parte-se da premissa de que o entendimento advindo da sociomaterialidade e das lógicas institucionais associadas às PCG pode evidenciar elementos teóricos e conceituais que contribuam com a compreensão sobre quais fatores externos e internos à organização as influenciam como instituições, e de que modo tais influências podem alterar seus comportamentos. Por meio da observação advinda de sua sociomaterialidade e da integração com a teoria existente, pode-se questionar os porquês das causalidades identificadas e, dessa forma, contribuir para o enriquecimento da teoria.

Sabe-se, entretanto, que as organizações utilizam diversas PCG simultaneamente (Guerreiro et al., 2011; Oyadomari, Mendonça, Cardoso, \& Lima, 2008). Com isso, a fim de delimitar esta pesquisa, partiu-se da premissa de que, entre as PCG existentes em cada organização, existe uma que é percebida por seus usuários como a mais usada.

Dessa forma, apresenta-se, a seguir, a questão que norteou esta pesquisa: Como avaliar a percepção dos gestores sobre a sociomaterialidade da PCG mais usada em sua organização, sob a ótica de sua cerimonialidade e/ou instrumentalidade advindas das diferentes lógicas institucionais?

Partindo da questão de pesquisa, o objetivo principal deste trabalho é propor um constructo que contribua com a compreensão sobre a percepção dos gestores, sobre a sociomaterialidade da prática de Contabilidade Gerencial mais utilizada em sua organização, com base na lógica institucional cerimonial versus instrumental.

O trabalho se justifica pela ausência de estudos que examinam a sociomaterialidade das PCG como instituições, e os seus efeitos na transformação dos contextos sociais dentro 
das organizações (Jones et al., 2013). Também se justifica pelo fato de proporcionar uma abordagem inovadora em pesquisa sobre PCG, com base na Teoria Institucional.

Espera-se contribuir para a evolução teórica da NIS, aprofundando a discussão da utilidade das PCG, por meio do entendimento de seus significados sobre a sociomaterialidade (cerimonial versus instrumental), no ambiente interno das organizações de grande porte não financeiras que atuam no Brasil.

\section{REVISÃO TEÓRICA}

\section{Nova Sociologia Institucional}

A Nova Sociologia Institucional (NIS) é uma das vertentes da Teoria Institucional e se concentra, predominantemente, em analisar os efeitos de instituições extraorganizacionais (sociais, econômicos e políticos) nas práticas contábeis das organizações. Ela tem sido utilizada por pesquisadores para explicar a estabilidade e os processos de mudança das PCG (Burns \& Scapens, 2000; Oyadomari, Mendonça, Cardoso, \& Frezatti, 2008). Com base nela, é possível compreender que as organizações incorporam novas práticas por acreditar que elas auxiliarão a produção de produtos ou serviços e aumentarão sua legitimidade, mesmo que os resultados dessas decisões não sejam observados imediatamente (Meyer \& Rowan, 1977).

O processo pelo qual um novo elemento institucional é incorporado por uma organização é denominado institucionalização (Zucker, 1977). Pode-se considerar que o processo de institucionalização é decorrente da ação da inovação sobre o contexto organizacional, que é movida por forças externas à organização e que leva ao surgimento de novas instituições (Tolbert \& Zucker, 1999). Essas novas instituições, a princípio pouco estruturadas, passam por um processo de teorização e são levadas a atender duas necessidades básicas: a clara definição de um problema organizacional, reconhecido publicamente e que deve ser resolvido, e a justificação do arranjo estrutural formal com bases lógicas, por meio de teorias adequadas. Em decorrência desse processo, tais instituições passam a ser vistas como objetos, e são, então, difundidas pela organização, deparando-se com grupos de apoio e de resistência. Se forem utilizadas de maneira ampla por diversos usuários e por gerações sucessivas de atores organizacionais, elas poderão ser consideradas sedimentadas e totalmente institucionalizadas (Strang \& Meyer, 1993; Tolbert \& Zucker, 1999).

A difusão é acelerada e redirecionada em função do processo de teorização. Strang e Meyer (1993) definem teorização como o "desenvolvimento autoconsciente e a especificação de categorias abstratas na formulação de relações padronizadas, tais como cadeias de causa e efeito" (p. 492). Na visão de mundo socialmente construído, inserido num contexto cultural, a teorização contribui para que seja dado sentido a ele. 0 processo de teorização pode decorrer da partilha e alinhamento entre os atores participantes, que estabelecem um novo modelo ou adotam um modelo advindo de grupos de alta legitimidade (cientistas, intelectuais, profissionais com sucesso reconhecido publicamente) (Strang \& Meyer, 1993). Como consequência desse processo, surgem e podem ser difundidas PCG, tais como o BSC, o custeio por atividades (ABC Costing) e o Economic Value Aded $\left(E V A^{\circledR}\right)$, entre outras.

Novas PCG, quando aceitas pela organização, passam a ser adotadas e difundidas, chegando ao seu máximo percentual de adotantes (ponto de saturação da prática e de total difusão) e com sua máxima legitimidade. Pode-se considerar que, nessa condição, ela está totalmente institucionalizada. Sua manutenção dependerá da capacidade de continuar a gerar valor para os atores organizacionais. Se isso não ocorrer, ela começará a ser substituída por uma nova prática, iniciando-se seu processo de desinstitucionalização (Lawrence, Winn, \& Jennings, 2001).

0 conceito de instituição associado à formação de campos organizacionais leva em conta a formação de estruturas de dominação e considera a existência das forças isomórficas como responsáveis pelo processo de assemelhação das organizações (DiMaggio \& Powell, 1983). Esses autores identificaram três mecanismos, mediante os quais a mudança isomórfica institucional ocorre, e que são assim chamados: isomorfismo coercitivo (decorrente da persuasão, da formação de coalizões, da força dos governos e de suas leis, entre outros); isomorfismo mimético (causado pela incerteza e ambiguidade que encoraja a imitação); e isomorfismo normativo (advindo da profissionalização, de universidades e consultorias). Na visão de Scott (2001), esses três mecanismos fazem parte dos pilares da construção e sustentação das instituições, conforme apresentado no Quadro 1.

No Quadro 1, observa-se que os diferentes pilares (regulatório, normativo e cultural-cognitivo) apresentam lógicas institucionais diferentes que atuam sobre os atores, organizações e, consequentemente, sobre as PCG. No pilar regulatório, a conformidade do usuário com a PCG que the é imposta ocorre quando ele percebe que, apesar de imposta, ela tem utilidade em seu dia a dia. Dessa forma, a lógica que sustenta a conformidade desse pilar é a resolução de problemas (Scott, 2001). No pilar normativo, sua ênfase está associada à dimensão prescritiva, avaliativa e obrigatória na vida social, advinda das normas estabelecidas por atores proeminentes que definem papéis e 
alçadas, impõem restrições, mas conferem poder. Esse pilar pode ser visto como o estabilizador das crenças e normas sociais (Scott, 2001). No pilar cultural-cognitivo, a principal característica está associada à construção de percepções compartilhadas, que constituem a realidade social e conferem significado ao uso das PCG (Scott, 2001).

\section{Quadro 1. Os três pilares das instituições}

\begin{tabular}{l|l|l|l}
\hline \multirow{2}{*}{ Dimensão } & \multicolumn{2}{c}{ Pilares } \\
\cline { 2 - 4 } & Regulatório & Normativo & Cultural-cognitivo \\
\hline $\begin{array}{l}\text { Base de } \\
\text { conformidade }\end{array}$ & Utilidade & Obrigação social & $\begin{array}{l}\text { Tomado como certo (taken for granted) e } \\
\text { entendimentos compartilhados }\end{array}$ \\
\hline Base de ordem & Regras regulatórias & Expectativas obrigatórias & Esquemas constitutivos \\
\hline Mecanismos & Coercitivo & Normativo & Mimético \\
\hline Lógica & Instrumentalidade & Adequação & Ortodoxia \\
\hline Indicadores & Regras, leis e sanções & Certificação e acreditação & Crenças comuns, lógicas de ação compartilhadas \\
\hline $\begin{array}{l}\text { Base de } \\
\text { legitimidade }\end{array}$ & Legalmente sancionado & Moralmente governado & $\begin{array}{l}\text { Compreensível, reconhecível, sustentado } \\
\text { culturalmente }\end{array}$ \\
\hline
\end{tabular}

Fonte: Scott (2001, p. 52)

No Brasil e no exterior, existe uma profusão de pesquisas sobre práticas de contabilidade gerencial utilizando a Nova Teoria Institucional. Entre os trabalhos identificados, para os fins desta pesquisa, destacam-se os de Kostova e Roth (2002) e de Orlikowski (2007). Os primeiros analisaram, sob a ótica da cerimonialidade, a adoção de uma prática relacionada à gestão da qualidade em uma organização multinacional. Esses autores tinham por objetivo verificar se aquela prática gerava contribuições reais para a melhoria do desempenho da gestão da qualidade (de maneira ativa) ou se era usada somente como o cumprimento de um rito que lhes era imposto por sua matriz (ou seja, de modo cerimonial). O segundo trabalho analisou como as tecnologias no trabalho interagem com o contexto social e, ao mesmo tempo, são influenciadas por ele, caracterizando materialmente seu papel de agentes de transformação social, ou seja, sua sociomaterialidade.

\section{Operacionalização de constructo para pesquisas sobre a sociomaterialidade de PCG}

Como ponto de partida, considera-se que toda instituição é marcada pela cerimônia e rito (Meyer \& Rowan, 1977). Na medida em que a instituição está voltada a propósitos de resolução de problemas, ela ganha instrumentalidade, e isso the confere legitimidade, mesmo que, primariamente, ela seja identificada por sua cerimonialidade (Bush, 1983). Tal comportamento, entretanto, é mais dialógico do que dialético, ou seja, nas instituições, comportamentos cerimoniais e instrumentais, isoladamente, são abstrações mentais, pois, na realidade, ocorrem simultaneamente em cada instituição. A base dessa dicotomia está associada ao valor percebido que é dado a uma instituição, identificado pela forma como as instituições são socialmente percebidas, o que se dá com base em padrões de julgamento, que dão significado a comportamentos a eles associados (Bush, 1983).

A essência dessa distinção reside no fato de que valores cerimoniais são garantidos pelos usos e costumes, incorporam a hierarquia, as classes e a distinção entre indivíduos, e racionalizam relações de poder, por meio de padrões de autoridade existentes no status quo e, dessa forma, estão ligados ao passado, enquanto valores instrumentais são garantidos pela aplicação sistemática de conhecimento para a resolução de problemas, por meio de um processo de questionamento de relacionamentos causais, e, dessa forma estão relacionados com o processo de mudança institucional (Bush, 1983).

Trazendo para o contexto da Contabilidade Gerencial, a sociomaterialidade de uma PCG pode ser considerada cerimonial quando ela atende a aspectos de funcionalidade técnica, mas não induz o gestor a agir com base nas informações por ela disponibilizadas. De outro lado, a sociomaterialidade de uma PCG pode ser instrumental quando, além de atender aos aspectos de funcionalidade técnica, promove a ação social, ou seja, o gestor toma decisões com base nas informações geradas por ela e, com isso, auxilia a promoção da mudança social. Para que o comportamento do uso de uma PCG seja considerado instrumental, deve-se associar a ele uma dimensão de valor instrumental. Da mesma forma, para que o comportamento do 
uso seja considerado cerimonial, a ele deve ser associado valor cerimonial. Em suma, o comportamento do uso de uma PCG será sempre dialógico, pois conterá parcelas de cerimonialidade e de instrumentalidade, em maior ou menor proporção. Por outro lado, os valores são dialéticos (cerimoniais ou instrumentais), e o que faz com que tais comportamentos sejam cerimoniais ou instrumentais é a sua associação com os valores. À medida que valores cerimoniais ou instrumentais são associados ao comportamento, configura-se sua cerimonialidade ou instrumentalidade, respectivamente (Bush, 1983).

Bush (1983) operacionalizou, dedutivamente, um aparato técnico-instrumental que possibilita qualificar adequadamente os estados transitórios dos comportamentos do uso de PCG entre totalmente cerimonial e totalmente instrumental. Chamados pelo autor de "estados de dominância dos valores cerimoniais versus os instrumentais", os quais podem ser identificados nos processos de institucionalização, eles geram a base para a dedução de axiomas, teoremas e corolários, que possibilitam estruturar abordagens empíricas sustentadas em hipóteses sobre o processo de mudança institucional. São apresentados, a seguir, alguns desses conceitos, adequando-os aos propósitos desta pesquisa.

Parte-se da premissa de que "um sistema conceitual incorpora suposições de fato, causa e valor (no sentido cotidiano do termo) que os usuários consideram verdadeiras, juntamente com princípios de inferência lógica que servem para aduzir implicações conjuntas das suposições”. Também se considera que "cada sistema conceitual é uma instituição ... e que sistemas conceituais distintos podem existir em uma sociedade e servir como métodos alternativos de racionalização do comportamento" (Edgren, 1996, p. 1026). Dessa forma, pode-se imaginar a existência de inúmeros sistemas conceituais dados os diferentes contextos organizacionais.

Dentro desse enfoque, Edgren (1996) considera inadequados os conceitos usados por Bush $(1983,1987)$ para a conceituação de valor, pela dificuldade em se diferenciar mito e ciência e, correspondentemente, cerimonial e instrumental. De outro lado, deve-se considerar que Paul Bush forneceu uma base formal para a teoria e para a construção de uma metodologia para pesquisa com base na Teoria Institucional para auxiliar tanto o desenvolvimento teórico como as aplicações em estudos empíricos, com potencial para contribuir com o desenvolvimento teórico e aplicações práticas nas instituições, entretanto o próprio Bush (1983) salienta que seu modelo analítico exigiria extensão e refinamento (Hayden, 2009; Hodgson, 2003). Sabe-se da dificuldade em conseguir utilizar os conceitos relacionados com as definições de valor usadas por Bush $(1983,1987)$, daí uma valorização adicional para esta pesquisa, pelo fato de que ela se destaca por sua proposta em operacionalizar o modelo de Bush $(1983,1987)$ para PCG usadas em organizações não financeiras de grande porte que operam no Brasil.

Dentro desse contexto, uma PCG, entendida como uma instituição, pode ser definida como um conjunto de padrões, prescritos socialmente, de comportamentos correlacionados a valores. O conjunto de comportamentos prescritos, $\mathrm{H}$, contém dois subconjuntos: (1) o subconjunto de comportamentos, C, e (2) o subconjunto de valores, $\mathrm{V}$, que se correlacionam com o comportamento. Em símbolos: $H=\{C, V\}$ (Bush, 1983, p. 39).

O conjunto de valores, $V$, contém dois subconjuntos separados: (1) valores garantidos cerimonialmente, $V_{c}$, e (2) valores garantidos instrumentalmente, $V_{i}$. Valores cerimoniais são ligados por uma lógica de "razão suficiente" e garantidos por padrões de comportamento tradicionais inseridos no status quo. Os valores instrumentais requerem a lógica das "causas eficientes" e são garantidos por uma continuidade causal. Eles proveem as bases para a solução dos problemas das organizações (Bush, 1983, p. 39).

O conjunto de comportamentos, C, é formado por dois subconjuntos e suas intersecções. Os dois subconjuntos são: (1) comportamento cerimonial, $C_{c}$; e (2) comportamento instrumental, $C_{i}$. A intersecção dos conjuntos $C_{c}$ e $C_{i}$ é $C_{c i}$, a qual tem um comportamento de significância cerimonial e instrumental, simultaneamente. Para cada $C$, há um V associado. Assim, $V_{c}$ pode ser associado $\operatorname{com} C_{c}, C_{i}$ ou $C_{c i}$. Uma vez que os valores garantidos cerimonialmente justifiquem a lógica de "razão suficiente", eles podem ser usados para racionalizar qualquer forma de comportamento. Também $V_{i}$ pode ser associado com $C_{i}$ ou $C_{c i}$, mas não $\operatorname{com} C_{c}$. Uma vez que valores instrumentalmente garantidos incorporam a lógica das “causas eficientes”, eles não podem racionalizar um comportamento de caráter puramente cerimonial (Bush, 1983, pp. 39-40).

A lógica que sustenta o processo dedutivo de Bush (1983) reside em seu entendimento de que as instituições estão em constante transformação, e os comportamentos a elas associados são influenciados por valores presentes onde elas se encontram. No entendimento de Bush (1983), valores instrumentais poderão estar somente associados a comportamentos mistos ou instrumentais. Já os valores cerimoniais poderão estar associados aos comportamentos cerimoniais, mistos ou instrumentais. Dessa forma, a expressão CV C, que é lida como V que correlaciona C com $C$, expressa as diversas possibilidades de transformação de um comportamento (seja ele cerimonial, misto ou instrumental), em virtude de sua submissão a valores organizacionais (cerimoniais ou instrumentais), em novos comportamentos (cerimoniais, mistos ou instrumentais). 
Como consequência desse processo dedutivo, Bush (1983) apresenta o conjunto de todas as possibilidades de padrões comportamentais, associando-os aos valores cerimoniais e instrumentais, e dividindo-os em dois subconjuntos: 1) o conjunto de padrões de comportamento garantidos cerimonialmente; e 2) o conjunto de padrões comportamentais garantidos instrumentalmente. Esse conjunto de possibilidades, que, em nosso estudo, está sendo chamado de sociomaterialidade das PCGs, pode ser visto no Quadro 2.

\section{Quadro 2. Conjunto de possibilidades de padrões comportamentais}

\begin{tabular}{l|c|c|c|c|c}
\hline Comportamento do uso & Cerimonial & Instrumental & Misto & Misto & Instrumental \\
\hline Valor associado & Cerimonial & Instrumental & Instrumental & Cerimonial & Cerimonial \\
\hline $\begin{array}{l}\text { Classificação do comportamento } \\
\text { segundo Bush (1983) }\end{array}$ & $C_{c} V_{c} C_{c}$ & $C_{i} V_{i} C_{i}$ & $C_{i} V_{i} C_{c i}$ & $C_{c} V_{c} C_{c i}$ \\
$C_{c i} V_{i} C_{c i}$ & $C_{c i} V_{c} C_{i}$ \\
\hline
\end{tabular}

Fonte: Bush (1983, pp. 40-41).

Analisando-se o processo de mudança institucional, com base nas informações apresentadas no Quadro 2, a partir do comportamento cerimonial garantido pelo valor cerimonial $\left(C_{c} V_{c}\right.$ $C_{c}$ ), observa-se que um comportamento cerimonial submetido a valores cerimoniais se mantém como um valor cerimonial; de outro lado, no comportamento instrumental garantido pelo valor cerimonial $\left(C_{c} V_{c} C_{i}\right)$, observa-se que um mesmo comportamento cerimonial garantido por um valor cerimonial é levado a um comportamento instrumental. Como explicar tal diferença no processo de mudança, sendo que ambas as instituições partiram de um comportamento cerimonial e estão sujeitas a valores cerimoniais?

No entendimento de Bush (1983, p. 52), o processo de mudança institucional ocorre em dois estágios: no primeiro, ocorre o encapsulamento de um comportamento instrumental, e, no segundo, ele é incorporado à instituição. Bush (1987, pp. 1094 1103) classifica três tipos de encapsulamentos: a) "conectado com o passado", observado em processos de mudança, porém com maior resistência, nos quais as tecnologias são vistas como ameaças à estabilidade cerimonial; b) "conectado com o futuro", observado em contextos nos quais as inovações são absorvidas com maior facilidade e são entendidas como capazes de promover o aumento do valor social da prática; e c) “desconectado", em que não há associação entre os resultados futuros esperados e o valor encapsulado na instituição, e que, por isso, pode resultar em retrocesso de valor para a organização. Os encapsulamentos “conectado com o passado" e "conectado com o futuro" são considerados progressivos, apresentando o primeiro uma taxa de mudança mais lenta que o segundo; e o terceiro é considerado regressivo.

Com vistas à melhoria do desempenho institucional, o encapsulamento progressivo é desejável ao regressivo; entretanto, o processo de mudança progressiva institucional está limitado ao conjunto de valores que sustentam e agem nas organizações, interagindo com os comportamentos. Dessa forma, a partir de um determinado momento, novas mudanças institucionais progressivas dependerão da expansão dessa base de valores (Bush, 1987). A Figura 1 apresenta a implicação da combinação entre valores e comportamentos, e a consequente sociomaterialidade das PCG.

\section{Figura 1. Sociomaterialidade cerimonial $\mathrm{x}$ instrumental de PCG}

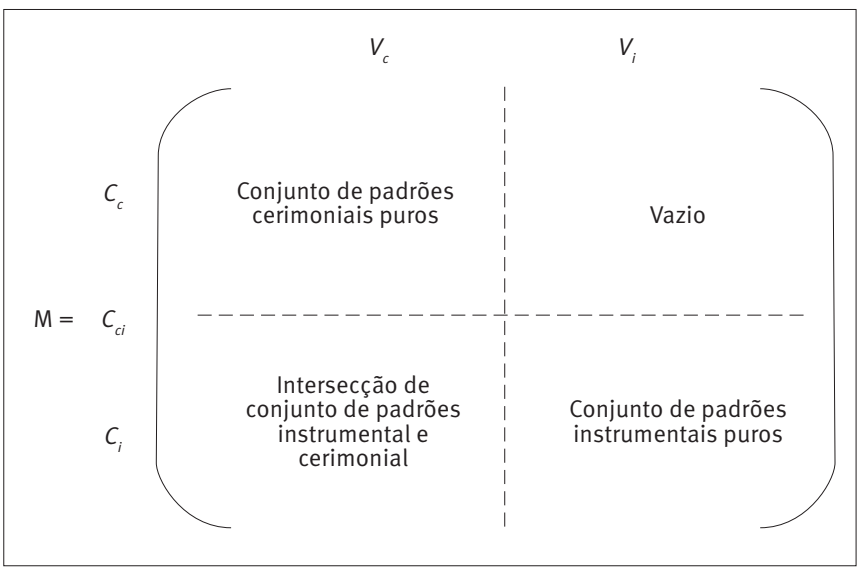

Fonte: Bush (1983).

Pode-se considerar que a base conceitual advinda da Teoria Institucional, que possibilita entender a lógica do processo de mudança descrito por Bush (1983), está associada à existência das contradições institucionais resultantes das diferentes lógicas e racionalidades institucionais, advindas das pressões isomórficas (normativa, coercitiva e mimética) externas 
à organização e das forças internas (atividade de teorização, a heterogeneidade dos usuários e o ímpeto para difusão), que levam à não adaptação das PCG aos contextos em que se encontram, promovendo, por meio da ação humana, de um lado, a busca pelo ganho de eficiência, ou, de outro, a manutenção do status quo (Seo \& Creed, 2002; Wanderley \& Soeiro, 2016).

Com base nos elementos apresentados, o próximo tópico apresenta o modelo teórico para a pesquisa.

\section{Modelo teórico para pesquisa de PCG com base na NIS}

Com base na revisão teórica efetuada sobre a NIS, apresenta-se, na Figura 2, um modelo teórico no qual se parte da premissa de que forças externas à organização agem sobre as PCG, criando tensões e contradições em função das diferentes lógicas advindas dessas forças, e que afetam a forma como interagem com o contexto social e como são percebidas, ou seja, sua sociomaterialidade (Bush, 1983, 1987; Seo \& Creed, 2002; Soeiro et al., 2016; Wanderley \& Soeiro, 2016). Como forças externas, nesse modelo são consideradas as pressões isomórficas: coercitivas, normativas e miméticas (DiMaggio \& Powell, 1983; Scott, 2001), e as forças internas são aquelas relacionadas com o processo de institucionalização, a saber: difusão, teorização, e heterogeneidade de usuários (Strang \& Meyer, 1993; Tolbert \& Zucker, 1999).

\section{Figura 2. Modelo teórico da pesquisa}

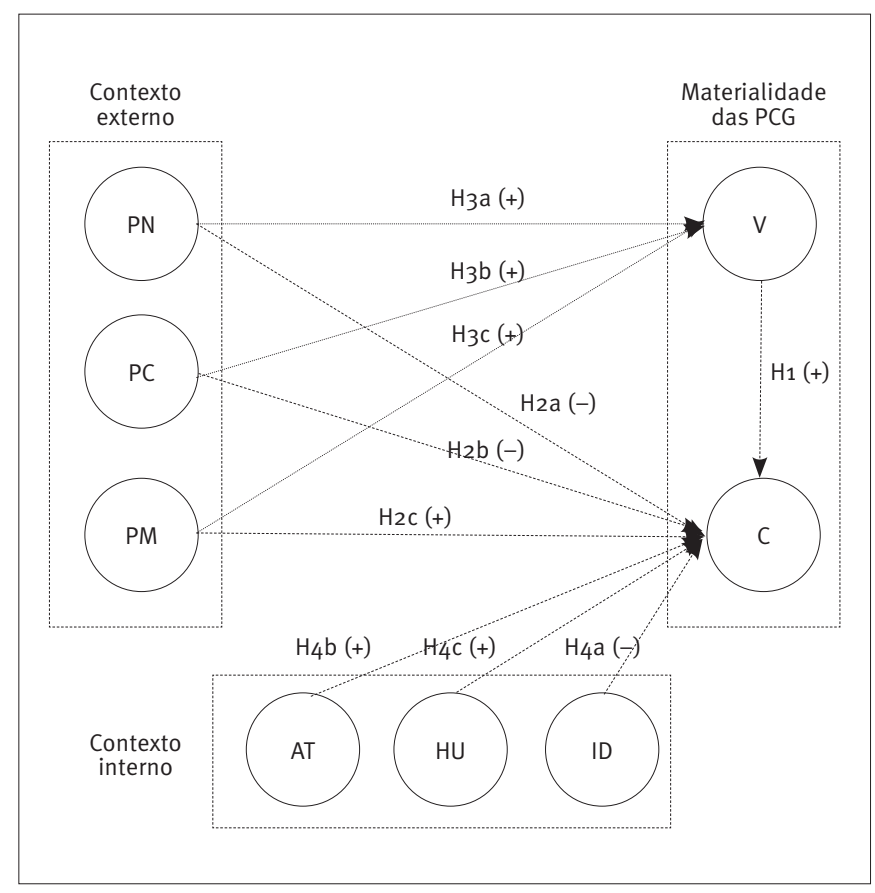

Onde: PN - pressões normativas; PC - pressões coercitivas; PM - pressões miméticas; AT - atividade de teorização; HU heterogeneidade dos usuários; ID - ímpeto para difusão; V = valores; e $\mathrm{C}=$ comportamento.

O modelo teórico elaborado com base na revisão da teoria apresenta 10 hipóteses, divididas em quatro grupos distintos. 0 primeiro testa a hipótese de que há associação positiva entre valor instrumental e comportamento instrumental. 0 segundo testa hipóteses de que há associação negativa entre pressões isomórficas normativas e coercitivas com o comportamento instrumental e positivas entre pressões miméticas e comportamento instrumental. O terceiro grupo testa hipóteses de que há associação positiva entre as pressões isomórficas (normativas, coercitivas e miméticas) e valores instrumentais. Por fim, o último testa hipóteses de que há associação positiva entre a atividade de teorização e heterogeneidade de usuários com comportamento instrumental e negativa entre ímpeto para difusão e comportamento instrumental.

\section{METODOLOGIA DE PESQUISA}

Estudos que se valem da Teoria Institucional são estruturados normalmente com base em uma abordagem qualitativa e com uma visão longitudinal (Burns \& Scapens, 2000), entretanto o estudo em questão valeu-se de uma abordagem transversal e quantitativa, uma vez que teve por objetivo propor um constructo que contribua com a compreensão dos fatores que atuam sobre a sociomaterialidade percebida por gestores com base na cerimonialidade e/ou instrumentalidade da PCG mais usada em organizações não financeiras de grande porte que operam no Brasil. Para tanto, fez-se necessário valer-se de modelos teóricos, estabelecimento e teste de hipóteses e da realização de um levantamento por amostragem (Martins \& Theóphilo, 2007), visando evidenciar elementos teóricos e conceituais que contribuam com o aumento do conhecimento sobre a sociomaterialidade da PCG mais usada por essas organizações. Tal abordagem pode ser considerada inovadora, seja pela utilização de uma abordagem transversal e quantitativa para estudos em Teoria Institucional, seja pela proposta de estudar a sociomaterialidade das PCG.

Foram escolhidos como respondentes profissionais que atuavam, há pelo menos um ano, em funções diretivas (diretor de contabilidade/controladoria, financeiro, geral) ou gerenciais (gerente de contabilidade/controladoria, financeiro ou controller). Os questionários buscavam investigar a percepção dos respondentes sobre a sociomaterialidade de práticas, o que 
pode ser subjetivo para profissionais que não compreendam o contexto organizacional no qual a PCG está inserida. Partiu-se da premissa de que tais profissionais estariam aptos a compreender os contextos investigados.

A definição por empresas de grande porte (com base nos critérios do Banco Nacional de Desenvolvimento Econômico e Social [BNDES], ou seja, receita bruta superior a $\mathrm{R} \$ 300$ milhões em 2015) ocorreu por se compreender que essas organizações são forçadas, por lei, a contratar auditorias externas, o que, de certa forma, colabora para o estabelecimento de um padrão mínimo de contabilidade. Empresas financeiras foram excluídas, uma vez que elas apresentam modelo de negócio diferente das não financeiras, o que poderia prejudicar a obtenção dos dados.

De acordo com dados obtidos com a edição Melhores \& Maiores de 2015, da revista EXAME, existiam em sua base de dados 1.153 organizações que atendiam às condições de porte e setor estabelecidas. Foram enviados questionários eletrônicos, no período de março a setembro de 2015, a 618 dessas empresas, cujas funções dos respondentes já haviam sido previamente identificadas. Foram obtidas 149 respostas completas, das quais 102 foram consideradas válidas, com base nos seguintes critérios adotados: (i) a organização deveria ser de grande porte, (ii) os respondentes deveriam ser profissionais que atuavam há pelo menos um ano em funções diretivas (diretor de contabilidade/controladoria, financeiro, geral) ou gerenciais (gerente de contabilidade/controladoria, financeiro ou controller) na organização estudada e (iii) deveriam ser usuários da PCG mais usada na organização. Salienta-se que a amostra não é probabilística, mas intencional, e que tal situação configura a impossibilidade de generalização dos achados.

O tamanho mínimo da amostra foi calculado com base no modelo estrutural proposto para esta pesquisa, que tem sete variáveis latentes, e com base na existência de sete preditores num mesmo nó (na variável latente comportamento - vide Figura 2). Por meio do uso do software G-Power $\left(\mathrm{f}^{2}=0,15\right.$, erro $=0,05$, $1-\beta=0,8)$, obteve-se que a quantidade mínima de respostas válidas para utilização da técnica de modelagem de equações estruturais seria de 103 observações (Hair, Hult, Ringle, \& Sarstedt, 2014). Durante a coleta dos dados, foram obtidas 102 observações válidas, e a diferença para o tamanho mínimo calculado foi considerada estatisticamente não significante (calculado pelo G-Power, o poder para $103=0.8004218$ e para $102=0.7954212$ )

Foram utilizadas duas técnicas de análise estatística dos dados: modelagem por equações estruturais e análise de correspondência. A primeira técnica trabalha com dados intervalares, enquanto a segunda usa dados nominais ou ordinais. A fim de manter o rigor metodológico, no questionário foi adotada uma escala de zero - equivalente a nenhuma concordância - a 10 - equivalente a total concordância - para classificar os dados. Para a realização da análise de correspondência, estabeleceram-se faixas com os dados nos processos de análise, conforme será descrito oportunamente. O questionário foi elaborado com base na revisão teórica e foi submetido duas vezes ao processo de validação qualitativa, por um grupo de cinco acadêmicos especialistas em Contabilidade Gerencial. A primeira rodada teve como objetivo analisar a aderência das questões com os objetivos das pesquisas, sua clareza, critérios para a identificação da PCG mais usada pelas organizações. A segunda visou analisar se as mudanças efetuadas atendiam às indicações propostas.

A caracterização da organização foi feita com base em seu segmento de atuação (indústria, comércio ou serviço), no controle do capital (nacional ou estrangeiro) e porte, o qual foi obtido por meio de uma lista de portes ajustados com base na classificação do BNDES (2011) e contemplava cinco faixas de receita bruta anual. Nosso foco eram empresas de porte "grande", com receita anual superior a $\mathrm{R} \$ 300$ milhões e inferior a $\mathrm{R} \$ 1$ bilhão; e “muito grande", com receita acima de $\mathrm{R} \$ 1$ bilhão. $A$ caracterização do respondente foi feita com base em sua função e tempo de exercício daquela função, na empresa estudada.

Foi solicitado ao respondente que informasse sua percepção sobre qual a PCG (uma única) mais usada em sua organização, a partir de uma lista de 17 PCG presentes no trabalho de Ferreira e Otley (2006), a saber: 1. planejamento estratégico; 2. orçamentos (budget); 3. análise de variações orçamentárias; 4. técnicas tradicionais de custeio; 5 . análises de rentabilidade de produtos; 6. painel de indicadores (tableau de bord); 7 . lucro residual; 8. retorno sobre investimento; 9. técnicas de pesquisa operacional; 10. balanced scorecard; 11. orçamento baseado em atividades; 12 . custeio baseado em atividades; 13 . custeioalvo (target costing); 14. análise de rentabilidade de clientes; 15. valor econômico adicionado (EVA $\left.{ }^{\circledR}\right) ; 16$. análise de ciclo de vida de produtos; 17. benchmarking; 18 . outros (descrever). Foi disponibilizado aos respondentes um glossário que explicava cada uma dessas opções.

Ao final dessa etapa, foi solicitado ao respondente que declarasse ser ou não usuário da PCG mais usada em sua organização. Os casos negativos foram invalidados, pois se entendeu que o respondente não estava apto a responder às demais questões, que envolviam o contexto de implantação e uso da PCG.

Os valores foram mensurados por meio de uma variável latente e reflexiva, com base no constructo "Fundo de Conhecimento" proposto por Foster (1981, como citado em Bush, 1987) e baseado nos seguintes fatores: disponibilidade 
de conhecimento, capacidade para entendimento e adaptações, e princípio do deslocamento mínimo (que considera que as mudanças propostas serão aceitas, desde que não gerem descontinuidade do “ecossistema” existente) (Bush, 1987, p. 1105). O questionário referente a essa variável foi estruturado com cinco assertivas.

Para a mensuração do comportamento de uso das PCG, foi utilizado o constructo de Mahama e Cheng (2013), que, por sua vez, se valeram do constructo de Adler e Borys (1996), baseado nos conceitos coercitivo versus capacitante, e que foi adaptado ao uso contábil por Ahrens e Chapman (2004), valendo-se das dimensões reparo, transparência interna, transparência global e flexibilidade. O questionário referente a essa variável foi estruturado com seis assertivas.

Para a mensuração das pressões isomórficas (normativas, coercitivas e miméticas), foram utilizados os pilares de Scott (2001), e o questionário referente a essas variáveis foi estruturado com 11 assertivas. Por fim, o questionário referente ao contexto institucional interno foi mensurado com base nas forças causais do processo de institucionalização identificadas por Tolbert e Zucker (1999), a saber: teorização, difusão e heterogeneidade dos usuários. O questionário referente a essas variáveis foi estruturado com oito assertivas.

Os dados obtidos após a análise descritiva foram submetidos à técnica de análise modelagem por meio de equações estruturais (Smart PLS - 2.o.M), pois ela busca atender a situações muito frequentes em pesquisas, em que a base de dados se caracteriza pela ausência de distribuições simétricas das variáveis mensuradas e por quantidade pequena de dados (Ringle, Silva, \& Bido, 2014). Posteriormente foram realizadas análises multivariadas por meio da técnica de análise de correspondência (STATA/SE 13.0), a fim de avaliar a associação entre as variáveis.

A utilização do processo de modelagem por meio de equações estruturais possibilitou a avaliação do modelo teórico proposto, e a obtenção de cargas fatoriais das variáveis latentes valor e comportamento, associadas a cada uma das observações. Com base nesse processo de análise estatística, foi possível classificar e avaliar a sociomaterialidade das PCG, sob a ótica de sua cerimonialidade e instrumentalidade.

Para realizar a análise da associação entre as duas variáveis latentes ( $\mathrm{V}$ e C), foram considerados os escores obtidos dessas variáveis, por meio do software PLS para cada observação. Para a variável comportamento (C), foi calculada a amplitude total ("máximo valor do escore C" menos o "mínimo valor do escore C"), que foi dividida por três (em função das três faixas identificadas na teoria - comportamento instrumental, cerimonial e misto).
Para a variável valor (V), foi seguido o mesmo procedimento, entretanto a amplitude total foi dividida por dois, estabelecendo duas categorias (valor cerimonial e valor instrumental), com base na teoria. Primeiramente, foram realizados testes de análise de correspondência entre elas e as demais variáveis de controle, e, posteriormente, somente entre elas.

\section{APRESENTAÇÃO E DISCUSSÃO SOBRE OS ACHADOS DE PESQUISA}

Os resultados demonstram que a PCG mais usada nas organizações estudadas foi o orçamento empresarial $(29,4 \%)$, seguido do planejamento estratégico $(27,5 \%)$ e das análises de variações orçamentárias (26,5\%). Foram realizadas análises multivariadas entre as PCG mais usadas e demais variáveis de controle (setor, porte, controle, função, tempo de empresa), e não foram obtidas evidências estatísticas de associações entre elas. Salienta-se, entretanto, que as PCG mais usadas representam uma classe de prática, por meio da qual se analisará sua sociomaterialidade, nas diferentes organizações estudadas. Os setores de atividades das organizações estudadas foram prioritariamente a indústria (com 58,8\%), seguida dos serviços (com 25,5\%), e, por fim, o comércio (com 15,7\%). Entre os 102 respondentes, estavam prioritariamente os gerentes (com $40,0 \%$ ), seguidos dos controllers (com 30,4\%), diretores (com $18,6 \%$ ), e, por fim, por um superintendente (com 1\%). A função de superintendente não fazia parte da lista original, entretanto um dos respondentes a indicou como sua função, e ela foi aceita entre as funções válidas, pois se enquadra na mesma faixa funcional das anteriores, para os fins desta pesquisa.

O modelo de mensuração foi testado seguindo os procedimentos de verificação de confiabilidade composta e Alfa de Cronbach (Hair et al., 2014). Para que a validade convergente do modelo de mensuração seja considerada boa, os indicadores devem idealmente ter carga superior a o,7 ou pelo menos valores de cargas maiores nas VLs originais do que em outras. Dentro desse propósito, foram suprimidos indicadores das variáveis latentes AT, CI, ID, HU e PN (Chin, 1998; Hair et al., 2014).

A confiabilidade do modelo foi avaliada por meio dos critérios de confiabilidade composta e Alfa de Cronbach. Ambas as medidas devem ser superiores a 0,7 (Hair et al., 2014). Conforme pode ser observado na Tabela 1, todas as VLs foram consideradas válidas pelo critério da confiabilidade composta. Pelo critério do Alfa de Cronbach, não foi considerado válido somente o constructo PC, porém foi mantido dada sua relevância para o modelo proposto (Chin, 1998; Hair et al., 2014). 
Tabela 1. Comparação entre confiabilidade composta e correlação entre constructos

\begin{tabular}{|c|c|c|c|c|c|c|c|c|}
\hline & AT & $\mathrm{Cl}$ & VI & HU & ID & PC & PM & PN \\
\hline $\mathrm{Cl}$ & 0,3147 & 0,7682 & & & & & & \\
\hline VI & 0,4744 & 0,4498 & 0,7884 & & & & & \\
\hline $\mathrm{HU}$ & 0,3631 & 0,2425 & 0,4351 & 0,9271 & & & & \\
\hline PC & 0,1094 & 0,4592 & 0,3771 & 0,1264 & 0,4791 & 0,7439 & & \\
\hline PM & 0,4304 & 0,4558 & 0,6372 & 0,3830 & 0,4805 & 0,4112 & 0,8119 & \\
\hline PN & 0,3013 & 0,3637 & 0,6252 & 0,4138 & 0,5355 & 0,6113 & 0,7001 & 0,8337 \\
\hline Alfa de Cronbach & 1,0000 & 0,8252 & 0,8473 & 0,8367 & 0,8599 & 0,6021 & 0,8363 & 0,7808 \\
\hline
\end{tabular}

Posteriormente, o modelo estrutural foi avaliado pela determinação dos coeficientes de determinação de Pearson $\left(R^{2}\right)$ das variáveis dependentes $\mathrm{V}$ - valor e $\mathrm{C}$ - comportamento. Os $R^{2}$ avaliam a porção da variância das variáveis endógenas, que é explicada pelo modelo estrutural. Indica a qualidade do modelo ajustado (Ringle et al., 2014). Para a área de Ciências Sociais e Comportamentais, Cohen (1988) sugere que $\mathrm{R}^{2}=2 \%$ seja classificado como efeito pequeno, $R^{2}=13 \%$ como efeito médio e $R^{2}=26 \%$ como efeito grande. $0 R^{2}$ foi ajustado para refletir o número de preditores e tamanho da amostra (102 cases e o número de preditores para variável latente $\mathrm{C}=7$ e para $\mathrm{V}=3$ ).

Observa-se na Tabela 2, com base nos critérios de Cohen (1988), que o $R^{2}$ ajustado das variáveis latentes $C\left(R^{2}=0,34\right)$ e V $\left(R^{2}=0,45\right)$ podem ser considerados de grande efeito para a área de Ciências Sociais. Também são analisados os valor-t, calculados por meio do algoritmo do bootstrapping para avaliar a significância das regressões e os valor-p de cada uma considerando 999 graus liberdade, uma vez que o bootstrapping fez 1.000 simulações.

\section{Tabela 2. Resultados da regressão}

\begin{tabular}{|c|c|c|c|c|c|c|c|}
\hline & $\begin{array}{l}\text { Coeficiente } \\
\text { estrutural }\end{array}$ & Erro padrão & Valor-t & Valor-p & Sig. & $\mathrm{R}^{2}$ & $\mathrm{R}^{2}$ ajustado \\
\hline AT $\rightarrow C$ & 0,1436 & 0,1179 & 1,2176 & 0,2237 & Não Sig. & \multirow{6}{*}{0,3875} & \multirow{6}{*}{$0,3419^{a}$} \\
\hline$V \rightarrow C$ & 0,2651 & 0,1300 & 2,0388 & 0,0417 & Sig. A $5 \%$ & & \\
\hline $\mathrm{HU} \rightarrow \mathrm{C}$ & 0,0944 & 0,1011 & 0,9338 & 0,3506 & Não Sig. & & \\
\hline$P C \rightarrow C$ & 0,4778 & 0,1809 & 2,6410 & 0,0084 & Sig. A $5 \%$ & & \\
\hline$P M \rightarrow C$ & 0,2737 & 0,1402 & 1,9519 & 0,0512 & Sig. A $10 \%$ & & \\
\hline$P N->C$ & $-0,2487$ & 0,2068 & 1,2029 & 0,2293 & Não Sig. & & \\
\hline$P N ~>>V$ & 0,3497 & 0,1292 & 2,7078 & 0,0069 & Sig. A $5 \%$ & 0,4689 & $0,4526^{b}$ \\
\hline
\end{tabular}

${ }^{\mathrm{a}}$ amostra $=102$, preditores $=7{ }^{\mathrm{b}}$ amostra $=102$, preditores $=3$ 
Cabe salientar que as relações entre as variáveis AT (atividade de teorização), HU (heterogeneidade dos usuários), PN (pressões normativas) e a variável C (comportamento) foram consideradas não significantes; e o mesmo ocorreu com a relação entre a variável PC (pressões coercitivas) e a variável V (valor).

É possível afirmar, com base nos resultados obtidos pelas equações estruturais, que o valor instrumental é afetado positivamente pelas pressões normativas e miméticas. Entende-se que a base de conhecimento é que sustenta os valores organizacionais e que ela é ampliada por essas pressões, e, com isso, os valores instrumentais têm oportunidade de se fazerem presentes e contribuírem com o processo de mudança institucional (Bush, 1983, 1987). Também pode-se afirmar que o C (comportamento) é afetado positivamente por V (valor), por PC (pressões coercitivas) e por PM (pressões miméticas). Nessas relações, identifica-se o processo de encapsulamento dos novos valores, sejam eles “voltados ao futuro", que promovem uma mudança mais intensa em direção à instrumentalização, sejam eles "voltados ao passado" com uma mudança de maneira menos intensa, em que os aspectos simbólicos e cerimoniais estão mais presentes. De outro lado, observa-se que C (comportamento) é afetado negativamente por PN (pressões normativas) e por ID (ímpeto para difusão). Identifica-se que tanto as PN como os processos de difusão (voltados para a normatização) levam à utilização das PCG de modo cerimonial e para o cumprimento de ritos, não estando associados com uma relação causal para a resolução de problemas, conforme é o esperado para o uso instrumental de uma PCG.

Valendo-se das cargas fatoriais das variáveis latentes $V$ e $C$, foram estabelecidas faixas (conforme descrito na metodologia) e elaboradas análises multivariadas para identificar a associação entre elas, conforme pode ser observado na Tabelaz.

\section{Tabela 3. Contingenciamento entre as categorias comportamento e valor}

\begin{tabular}{l|c|c|c|c}
\hline \multirow{2}{*}{ Valor } & \multicolumn{4}{|c}{ Comportamento } \\
\cline { 2 - 5 } & C-Cerimon & C-Misto & C-Instrum & Total \\
\hline V-Cerimonial & 2 & 9 & 6 & 17 \\
\hline V- Instrumental & 3 & 18 & 64 & 85 \\
\hline Total & 5 & 27 & 70 & 102 \\
\hline
\end{tabular}

Nota: Pearson $\operatorname{chi}^{2}(2)=10.6629-\mathrm{Pr}=0,00480$ contingenciamento entre comportamento e valor, observado na Tabela 3, testado pelo $\mathrm{Chi}^{2}(\mathrm{p}=0,0048<$

0,05), revela que essas variáveis não são independentes, ou seja, comportamento

e valor não se combinam aleatoriamente no conjunto de observações analisadas (Hair et al., 2014)
Com base nessa evidência, e analisando-se a sociomaterialidade das PCG mais usadas nas organizações investigadas, pode-se inferir que:

- Onde as PCG foram percebidas cerimonialmente, isso pode estar associado a diversos elementos, a saber:

> Nessas organizações, as PCG são percebidas principalmente por seu papel simbólico, e seu uso deve estar associado prioritariamente a ritos. Pode-se considerar que elas sejam vistas como tecnologias mais coercitivas (Adler e Borys, 1996).

> Empiricamente ficou constatado que:

» há associação positiva entre PN (pressões normativas), PM (pressões miméticas) e V (valor - aumento da instrumentalidade), e, considerando-se que há associação positiva $V$ (valor - instrumental) com C (comportamento instrumental), pode-se inferir que as organizações que se encontram nesse tipo de comportamento de uso provavelmente estão com baixo nível de pressões externas (PN e PM);

» há associação negativa entre PN (pressões normativas) e C (comportamento) e ID (ímpeto para difusão) e C (comportamento), e, dessa forma, pode-se considerar que os efeitos advindos dessas forças criam estruturas por meio de mecanismos normativos e têm como base de conformidade a obrigação social. A lógica institucional decorrente dessas forças está relacionada com a adequação do uso da PCG às necessidades da organização, com base na visão do atendimento aos interesses de um grupo dominante, e o comportamento percebido do seu uso, ou seja, sua sociomaterialidade, que se dá do imbricamento entre social e tecnológico é o uso cerimonial (Orlikowski, 2007, 2010; Orlikowski \& Scott, 2008; Scott, 2001; Wagner, Moll, \& Newell, 2011).

> Em suma, a lógica institucional associa elementos de uma dimensão macro (forças externas, processos de difusão) à elementos de um universo micro (a sociomaterialidade da PCG) em resposta às forças ligadas à normatização, que oferece, nesse contexto, 
como base de legitimidade, a percepção de que a PCG é moralmente governada, e, como resultado, tem-se o seu uso com base no simbolismo e o comportamento cerimonial (Scott, 2001; Thornton \& Ocasio, 2008; Wanderley \& Soeiro, 2016). Nessas organizações, pode-se considerar que o processo de encapsulamento é do tipo conectado com o passado, ou seja, os valores oferecem elementos instrumentais, entretanto eles estão encapsulados na prática, que tem um olhar para o passado. 0 processo de transformação do comportamento de uso dessas PCG de cerimonial para instrumental somente ocorrerá se houve um aumento muito intenso na base de valores, ou se houver um aumento expressivo dos níveis de tensões, do contrário os valores permanecerão somente encapsulados (Bush, 1983, 1987).

> Para exemplo da sociomaterialidade das PCG nessas organizações, pode-se considerar o uso do orçamento empresarial. Nessas organizações, pode-se considerar que ele estará implementado e será acompanhado conforme o estabelecido nas normas da organização; entretanto, se forem identificadas variações (planejado x realizado), pouca ou nenhuma ação ocorrerá. Não se buscará aprender, com o uso da PCG, meios para alterar a realidade; simplesmente ele será usado sem consequências. Manter-se-á a lógica das conveniências sociais.

> Dessa forma, apesar de as PCGs serem usadas nessas organizações, as mudanças sociais decorrentes de tal uso são fracas, porque os valores que sustentam esse comportamento estão associados a estruturas hierárquicas rígidas, que dificultam os processos de mudança e privilegiam a manutenção do status quo (Bush, 1983, 1987). Também se pode conjecturar que, nessas organizações, os níveis de tensão causados pelas diferentes racionalidades e lógicas institucionais sejam baixos (Soeiro, Miranda, \& Araújo, 2016; Seo \& Creed, 2002; Wanderley \& Soeiro, 2016), e que o processo de encapsulamento seja do tipo “conectado com o passado” (Bush, 1983).

- Onde elas foram percebidas instrumentalmente, isso pode estar associado a diversos elementos, a saber:
> Nessas organizações, as PCGs são percebidas principalmente por seu papel instrumental, e seu uso deve estar associado prioritariamente à ação causal para a resolução de problemas. Pode-se considerar que elas são vistas como tecnologias capacitantes (Adler \& Borys, 1996).

> Tem-se em conta que, empiricamente, ficou constatado que:

» da mesma forma que na situação anterior, as associações entre pressões isomórficas e valor se mantêm, entretanto pode-se inferir que as organizações que se encontram nesse tipo de comportamento de uso provavelmente estão sob alto nível de pressões externas (PC e PM);

» há associação positiva entre PM (pressões miméticas), PC (pressões coercitivas) e C (Comportamento); essas forças têm como base de conformidade os entendimentos compartilhados que levam aos taken for granted e a utilidade (respectivamente) (Scott, 2001). As lógicas institucionais decorrentes dessas forças estão relacionadas com a ortodoxia e a instrumentalidade, e o comportamento percebido do seu uso, ou seja, sua sociomaterialidade, que se dá do imbricamento entre social e tecnológico, é o do uso instrumental (Orlikowski, 2007, 2010; Orlikowski \& Scott, 2008; Scott, 2001; Wagner, Moll, \& Newell, 2011).

> Em suma, a lógica institucional associa elementos de uma dimensão macro (forças externas, processos de difusão) a elementos de um universo micro (a sociomaterialidade da PCG) como resposta às forças ligadas ao mimetismo e à coerção estão associados ao fato de que essas PCG precisam ser compreensíveis, reconhecíveis, e partilhar suas lógicas com os atores organizacionais que delas se valem (quando associadas às pressões miméticas), e assegurar que aquilo que foi legalmente sancionado esteja em uso, contribuindo com as mudanças esperadas (quando associadas às pressões coercitivas) para que alcancem a legitimidade; como resultado, têm-se o seu uso com base na instrumentalidade e observa-se o comportamento instrumental (Scott, 2001; Thornton \& Ocasio, 2008; Wanderley \& Soeiro, 2016). Nessas 
organizações, pode-se considerar que o processo de encapsulamento é do tipo conectado com o futuro, ou seja, os valores oferecem elementos instrumentais que são encapsulados na prática, que tem um olhar para o futuro. 0 processo de transformação do comportamento de uso dessas PCG de cerimonial para instrumental ocorrerá ou se manterá em instrumental. Entretanto, é importante que haja um incremento contínuo na base de valores e nos níveis de tensões, do contrário os valores encapsulados poderão ser alterados para o do tipo conectado com o passado (Bush, 1983, 1987).

> Como exemplo da sociomaterialidade das PCG nessas organizações, considerando-se o mesmo exemplo do orçamento empresarial, poder-se-ia inferir que, nessas organizações, esse instrumento, além de estar implantado, sofrerá ajustes sempre que se fizer necessário para o aumento de sua eficácia (com o intuito de resolver problemas de gestão com os quais estivesse associado). No dia a dia da organização, tanto o processo da execução como o controle orçamentário visarão resolver problemas; nesse sentido, as variações dos planos serão analisadas com o intuito de levar ao aprendizado. Manter-se-á a lógica das causas eficientes.

> Dessa forma, com o uso das PCGs nessas organizações, as mudanças sociais decorrentes de tal uso são intensas, porque os valores que sustentam esse comportamento estão associados a estruturas flexíveis ou dotadas de uma ampla base de valores, que facilitam os processos de mudança e privilegiam a relação causal para a resolução de problemas (Bush, 1983, 1987). Também se pode conjecturar que, nessas organizações, os níveis de tensão causados pelas diferentes racionalidades e lógicas institucionais sejam altos (Soeiro, Miranda, \& Araújo, 2016; Seo \& Creed, 2002; Wanderley \&
Soeiro, 2016), e que o processo de encapsulamento seja do tipo "conectado com o futuro" (Bush, 1983).

O Quadro 3 representa o constructo, que é objetivo dessa pesquisa, e oferece a síntese dos entendimentos sobre os tipos de percepção sociomaterial dos gestores sobre cada uma das PCG mais usada pelas organizações estudadas. Nela são apresentados os seguintes elementos: a) a classificação do comportamento segundo Bush (1983): $C_{c} V_{c} C_{c} ; C_{i} V_{i} C_{i} ; C_{i} V_{i} C_{c i} ; C_{c i} V_{i} C_{c i} ; C_{c} V_{c} C_{c i}$; $C_{c i} V_{c} C_{c i} ; C_{c} V_{c} C_{i}$ e $C_{c i} V_{c} C_{c i} ;$ b) o comportamento percebido da PCG: cerimonial, instrumental e/ou misto (cerimonial e instrumental); c) o valor conferido à PCG: cerimonial ou instrumental; d) o tipo de encapsulamento: conectado com o passado, conectado com o futuro e desconectado; e) forças externas e internas que atuam prioritariamente sobre as PCG: PM (pressões miméticas), PN (pressões normativas), PC (pressões coercitivas) e (ID) ímpeto para difusão; f) níveis de tensões institucionais: baixo, médio, alto; g) quantidade de organizações para cada tipo de grupo: de acordo com o grupo de respondentes; h) PCG mais usada: identificação com base na lista fornecida.

É possível observar que $69 \%$ das PCG mais usadas são percebidas nas organizações estudadas como instrumentais, ou seja, contribuem para a transformação dos contextos sociais nos quais estão inseridas; $26 \%$ são percebidas simultaneamente como simbólicas e instrumentais, ou seja, contribuem para a transformação de seus contextos sociais, mas também estão associadas a ritos e simbolismo; $2 \%$ são percebidas como cerimoniais, ou seja, estão focadas em ritos e simbolismo; e, por fim, 3\% também foram percebidas como cerimoniais, entretanto em decorrência de algum desalinhamento com seu conjunto de valores, o que deve contribuir, conforme a teoria proposta por Bush $(1983,1987)$, para a desagregação dessas organizações. Esse tipo de situação ocorre quando se confere status de instrumentalidade àquilo que é cerimonial e simbólico. Um dos exemplos clássicos para esse tipo de comportamento foi a postura adotada pelos nazistas, na Segunda Guerra Mundial, quando conferiam status científico para a depuração de uma “raça”, em detrimento da aniquilação de seres humanos.

\section{Quadro 3. Síntese dos achados da pesquisa}

\begin{tabular}{c|c|c|c|c|c|c|c|c}
\hline $\begin{array}{c}\text { Classificação de } \\
\text { comportamento } \\
\text { segundo Bush } \\
(\mathbf{1 9 8 3 )}\end{array}$ & Comportamento & Valor & Encapsulamento & $\begin{array}{c}\text { Força } \\
\text { prioritária } \\
\text { (externa) }\end{array}$ & $\begin{array}{c}\text { Força } \\
\text { prioritária } \\
\text { (interna) }\end{array}$ & $\begin{array}{c}\text { Tensões } \\
\text { institucionais }\end{array}$ & $\begin{array}{l}\text { Organi- } \\
\text { zações }\end{array}$ \\
\hline$C_{c} V_{c} C_{c}$ & Cerimonial & Cerimonial mais usadas & $\begin{array}{c}\text { "conectado com } \\
\text { o passado" }\end{array}$ & PN & ID & Baixo & 2 & $\begin{array}{l}\text { Análise de variações } \\
\text { orçamentárias (1), e } \\
\text { orçamento baseado } \\
\text { em atividades (1) }\end{array}$ \\
\hline
\end{tabular}


Quadro 3.. Síntese dos achados da pesquisa

(continuação)

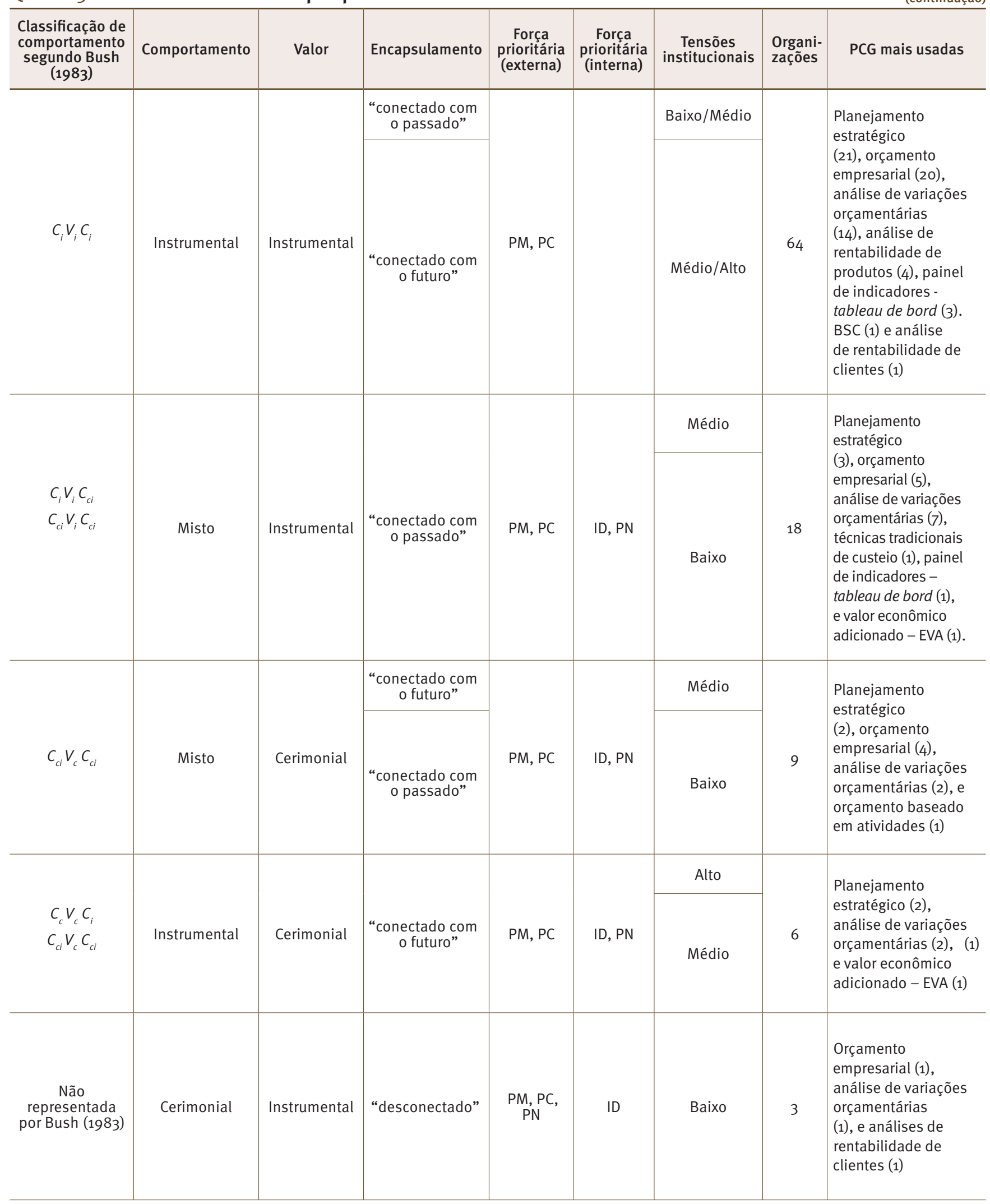




\section{CONSIDERAÇÕES FINAIS}

O objetivo principal do trabalho foi atingido, uma vez que foi possível propor um constructo que contribui com a compreensão sobre a percepção dos gestores quanto à sociomaterialidade da PCG mais utilizada em sua organização, com base na lógica institucional cerimonial versus instrumental. Com base nesse constructo, é possível compreender que as PCG são instituições que podem transformar os contextos onde estão inseridas, uma vez que fazem parte da práxis humana, e contribuem com a construção da realidade social ao longo do tempo e da história nas organizações em que estão inseridas. São decorrências do imbricamento entre humano, tecnológico e social, sendo impossivel distinguir onde uma dimensão começa e a outra acaba (Orlikowski, 2007). Estão inseridas em um contexto onde poderosas forças externas e internas atuam criando contextos com diferentes lógicas (Thornton \& Ocasio, 2008) e em diferentes níveis de tensões (Wanderley \& Soeiro, 2016), e, em resposta a essas pressões, elas (as PCG) se conformam e legitimam (Scott, 2001).

O constructo desenvolvido fornece elementos para a compressão dos contextos organizacionais, forças e processos internos que levam as práticas a adotarem diferentes comportamentos com base no par valor e comportamento, auxiliando o entendimento de como as forças atuam sobre as PCG, em que contextos estão inseridas, por que respondem da forma que respondem a essas pressões. Entende-se que a pesquisa atendeu a seus objetivos e possibilitou a edificação de elementos que ampliam o conhecimento sobre o comportamento das instituições, notadamente sobre a ótica das PCG, oferecendo contribuições para a teoria e para as organizações que poderão, por meio da utilização desse constructo, dar o uso mais adequado para as PCG que por elas são usadas, dentro de suas características peculiares de contextos.

Com base nos resultados empíricos, pode-se, também, conhecer que o uso prioritário (69\%) dado pelas organizações estudadas às PCG está associado à resolução de problemas, e, com isso, elas estão sociomaterialmente inseridas como conformadoras das realidades sociais nos contextos em que se encontram, como tecnologias transformadoras importantes para as organizações.

De acordo com a pesquisa, observou-se que as práticas relacionadas com o processo de planejamento e controle (orçamento empresarial e seu controle de variações, e planejamento estratégico) foram identificadas como as mais usadas pela maior parte das organizações pesquisadas (83\%), e, dado o foco na resolução de problemas, por meio delas, as organizações tentam antecipar fatos, maximizar a utilização de ativos e otimizar desempenhos, buscando a geração de valor para os atores sociais que com elas se relacionam. Observa-se, dessa forma, a relevância do uso das PCG para as organizações.

Como limitações desta pesquisa, destacam-se dois pontos: a) as respostas utilizadas foram obtidas por meio de um questionário; b) não foram realizadas entrevistas para o aprofundamento das percepções obtidas originalmente por meio dos questionários com nenhuma das empresas investigadas.

Sugere-se a realização de futuros trabalhos que possam se valer do constructo gerado nesta pesquisa, usando-o como um elemento prévio de investigação sobre a sociomaterialidade de práticas diversas (não necessariamente contábeis) em organizações, para amplas amostras (maiores que 100 casos), a fim de verificar se os achados se confirmam.

Também se recomenda o uso desse constructo como ferramenta para a seleção de casos para estudos aprofundados, partindo-se de amplas amostras. Entende-se que o uso desse constructo permitirá, a priori, maior assertividade na escolha de organizações com características desejadas para estudos de caso únicos ou múltiplos.

\section{REFERÊNCIAS}

Adler, P. S., \& Borys, B. (1996). Two types of bureaucracy: Enabling and coercive. Administrative Science Quarterly, 41(1), 61-89. doi:10.2307/2393986

Aguiar, A. B., \& Guerreiro, R. (2008). Processos de persistência e mudança de sistemas de contabilidade gerencial: Uma análise do paradigma institucional. Revista Universo Contábil, 4(3), 6-24

Ahrens, T., \& Chapman, C. S. (2004). Accounting for flexibility and efficiency: A field study of management control systems in a restaurant chain. Contemporary Accounting Research, 21(2), 271-301. doi:10.1506/vjr6-rp75-7gux-xhox

Banco Nacional de Desenvolvimento Econômico e Social. (2011). Circular $n^{0}$ 34, de 6 de setembro de 2011: Normas reguladoras do produto BNDES Automático. Recuperado de www.bndes.gov.br

Barley, S. R., \& Tolbert, P. S. (1997). Institutionalization and structuration : Studying the links between action and institution. Organization Studies, 18(1), 93-117. doi:10.1177/017084069701800106.

Beuren, I. M., Rengel, S., \& Rodrigues Junior, M. M. (2015). Relação dos atributos da contabilidade gerencial com os estágios do ciclo de vida organizacional. Innovar, 25(57), 63-78. doi:110.15446/innovar. v25n57.50328

Burns, J., \& Scapens, R. W. (2000). Conceptualizing management accounting change: An institutional framework. Management Account ing Research, 11(1), 3-25. doi:10.1006/mare.1999.0119

Bush, P. D. (1983). An exploration of the strucutal characteristics of a Veblen-Ayres-Foster defined institutional domain. Journal of Economic Issues, 27(1), 35-66. 
Bush, P. D. (1987). The theory of institutional change. Journal of Economic Issues, 21(3), 1075-1116. doi:10.1080/00213624.1987.11504697

Chin, W. W. (1998). The partial least squares approach for structural equation modeling. In G. A. Marcoulides (Ed.), Modern methods for business research (pp. 295-236). London, UK: Lawrence Erlbaum Associates.

Coase, R. H. (1937). The nature of the firm. Economica, 4(16), 386-405. doi:10.1111/j.1468-0335.1937.tboooo2.x

Cohen, J. (1988). Statistical power analysis for the behavioral sciences (2nd ed.). New York, USA: Psychology Press.

Davila, T. (2000). An empirical study on the drivers of management control systems' design in new product development. Accounting, Organizations and Society, 25(4-5), 383-409. doi:10.1016/S03613682(99)00034-3

DiMaggio, P. J., \& Powell, W. W. (1983). The iron cage revisited: Institutional isomorphism and collective rationality in organizational fields. American Sociological Review, 48(2), 147-160.

Edgren, J. (1996). Modeling institutional change: Some critical thoughts. Journal of Economic Issues, 30(4), 1017-1029.

Ferreira, A., \& Otley, D. (2006). Exploring inter and intra-relationships between the design and use of management control systems. Recuperado de http://ssrn.com/abstract $=896228$

Frezatti, F., Barroso, M. F. G., \& Carter, D. B. (2015). Discursos internos se sustentam sem suporte da contabilidade gerencial? Um estudo de caso no setor de autopeças. Organizações \& Sociedade, 22(75), 485-504. doi:10.1590/1984-9230751

Frezatti, F., Relvas, T. R. S., \& Junqueira, E. (2010). BSC e a estrutura de atributos da contabilidade gerencial: Uma análise no ambiente brasileiro. RAE-Revista de Administração de Empresas, 50(2), 187-198. doi:10.1590/So034-75902010000200005

Friedland, R. (2013). God, love and other good reasons for practice: Thinking through institutional logics. In M. Lounsbury, \& E. Boxenbaum (Eds.), Research in the sociology of organizations (Vol. 39, Part A - Institutional Logics in Action, pp. 25-50). Oxford, UK: Elsevier.

Friedland, R., \& Alford, R. B. (1991). Bringing society back in: Symbols, practices, and institutional contradictions. In W. W. Powell, \& P. J. DiMaggio (Eds.), The new institutionalism in organizational analysis (Chap. 10, pp. 232-266). Chicago, USA: Chicago University Press.

Guerreiro, R., Cornachione, E., Jr., \& Soutes, D. O. (2011). Empresas que se destacam pela qualidade das informações a seus usuários externos também se destacam pela utilização de artefatos modernos de contabilidade gerencial? Revista Contabilidade e Finanças, 22(55), 88-113. doi:10.1590/S1519-70772011000100006

Guerreiro, R., Frezatti, F., Lopes, A. B., \& Pereira, C. A. (2005). O entendimento da contabilidade gerencial sob a ótica da teoria institucional. Organizações \& Sociedade, 12(35), 91-106. doi:10.1590/S198492302005000400005

Hair, J. F., Jr., Hult, G. T. M., Ringle, C. M., \& Sarstedt, M. (2014). A primer on partial least squares structural equation modeling (PLS-SEM). Thousand Oaks, USA: Sage Publications.

Hall, P. A., \& Taylor, R. C. (2003). As três versões do neo-institucionalismo. Lua Nova: Revista de Cultura e Política, (58), 193-223. doi:10.1590/S0102-64452003000100010

Haydem, F. (2009). Normative analysis of instituted porcesses. In T.
Natarajan, W. Elsner, \& S. Fullwiler, S. (Eds.), Institutional analysis and praxis: The social fabric matrix approach (pp. 103-120). New York, USA: Springer.

Hodgson, G. M. (2003). El problema de la especificidad histórica. Investigación Económica, 62 (245), 33-69.

Jones, C., Boxenbaum, E., \& Anthony, G. (2013). The immateriality of the material in institutional logics. In M. Lounsbury, \& E. Boxenbaum (Eds.), Research in the sociology of organizations (Vol. 39, Part A Institutional Logics in Action, pp. 51-75). Wagon Lane: UK. Emerald Publishing.

Kostova, T., \& Roth, K. (2002). Adoption of an organizational practice by subsidiaries of multinational corporations: Institutional and relational effects. Academy of Management Journal, 45(1), 215-233. doi:10.2307/3069293

Lawrence, T. B., Winn, M. I., \& Jennings, P. D. (2001). The temporal dynamics of institutionalization. The Academy of Management Review, 26(4), 624-644.

Machado-da-Silva, C. L., Silva, V., \& Crubellate, J. M. (2005). Estrutura, agência e interpretação: Elementos para uma abordagem recursiva do processo de institucionalização. RAC-Revista de Administração Contemporânea 14(N. Esp.), 77-107. doi:10.1590/ S141565552010000600005

Mahama, H., \& Cheng, M. M. (2013). The effect of managers' enabling perceptions on costing system use, psychological empowerment, and task performance. Behavioral Research in Accounting, 25(1), 89114. doi:10.2308/bria-50333

Martins, G. A., \& Theóphilo, C. R. (2007). Metodologia da investigação científica para ciências sociais aplicadas. São Paulo, SP: Atlas.

Meyer, J. W., \& Rowan, B. (1977). Institutionalized organizations: Formal structure as myth and ceremony. American Journal of Sociology, 83(2), 340-363.

Orlikowski, W. J. (2007). Sociomaterial practices: Exploring technology at work. Organization Studies, 28(9), $1435-1448$. doi:10.1177/0170840607081138

Orlikowski, W. J. (2010). The sociomateriality of organisational life: Considering technology in management research. Cambridge Journal of Economics, 34(1), 125-141. doi:10.1093/cje/bepo58

Orlikowski, W. J., \& Scott, S. V. (2008). Sociomateriality: Challenging the separation of technology, work and organization. Academy of Management Annals, 2(1), 433-474. doi:10.1080/19416520802211644

Otley, D. T. (1978). Budget use and managerial performance. Journal of Accounting Research, 16(1), 122-149. doi:10.2307/2490414

Oyadomari, J. C. T., Mendonça, O. R., Neto, Cardoso, R. L., \& Frezatti, F. (2008). Análise dos fatores que favorecem a institucionalização da value based management (VBM) à luz dos argumentos teóricos da vertente new institutional sociology (NIS). Revista Universo Contábil, $4(2), 6-21$.

Oyadomari, J. C. T., Mendonça, O. R., Neto, Cardoso, R. L., \& Lima, M. P. D. E. (2008). Fatores que influenciam a adoção de artefatos de controle gerencial nas empresas brasileiras: Um estudo exploratório sob a ótica da teoria institucional. Revista de Contabilidade e Organizações, 2(2), 55-70. doi:10.11606/rco.v2i2.34705

Raey, T., \& Jones, C. (2015). Qualitatively capturing institutional logics. Strategic Organization, 14(14), 441-454. doi:10.1177/1476127015589981 
Ringle, C. M., Silva, D., \& Bido, D. (2014). Modelagem de equações estruturais com utilização do SmartPLS. Revista Brasileira de Marketing, 13(2), 56-73. doi:10.5585/remark.v13i2.2717

Scapens, R. W. (1994). Never mind the gap: Towards an institutional perspective on management accounting practice. Management Accounting Research, 5(3-4), 301-321. doi:10.1006/mare.1994.1019

Scott, W. R. (2001). Institutions and organizations (2nd ed.). Thousand Oaks, USA: Sage Publications.

Seo, M., \& Creed, W. E. D. (2002). Institutional contradictions, praxis, and institutional change: A dialetical perspective. Academy of Management Review, 27(2), 222-247.

Smets, M., \& Jarzakowski, P. (2013). Reconstructing institutional complexity in practice: A relational model of institutional work and complexity. Human Relations, 66(10), 1279-1309. doi:10.1177/0018726712471407

Soeiro, T. M., Miranda, L. C., \& Araújo, J. G. N. (2016). Contradição institucional e mudança na alta administração: O caso de uma empresa nordestina de tecnologia de informação. Revista Universo Contábil, 12(1), 162-177. doi:10.4270/ruc.2016109

Strang, D., \& Meyer, J. W. (1993). Institutional conditions for diffusion. Theory and Society, 22(4), 487-511. doi:10.1007/BFoog93595

Thornton, P. H., \& Ocasio, W. (2008). Institutional logics. In R. Greenwood, C. Oliver, R. Suddaby, \& K. Sahlin (Orgs.), The Sage handbook of organizational institutionalism, pp 99-129. London, UK: Sage.

Thornton, P. H., Ocasio, W., \& Lounsbury, M. (2012). The institutional logics perspective: A new approach to culture, structure and process. Oxford, USA: Oxford University Press.

Tolbert P. S., \& Zucker L. G. (1983). Institutional sources of change in the formal structure of organizations: The diffusion of civil service reform, 1880-1935. Administrative Science Quarterly, 28(1), 22-39. doi: $10.2307 / 2392383$

Tolbert, P. S., \& Zucker, L. G. (1999). A institucionalização da teoria institucional. In S. R. Clegg., C. Hardy, \& W. R. Nord (Orgs.), Handbook de estudos organizacionais (Vol. 1, Cap. 6, pp. 196-219). São Paulo, SP: Atlas.

Tuomela, T. S. (2005). The interplay of different levers of control: A case study of introducing a new performance measurement system. Management Accounting Research, 16(3), 293-320. doi:10.1016/j. mar.2005.06.003

Wagner, E. L., Moll, J., \& Newell, S. (2011). Accounting logics, reconfiguration of ERP systems and the emergence of new accounting practices: A sociomaterial perspective. Management Accounting Research, 22(3), 181-197. doi:10.1016/j.mar.2011.03.001

Wanderley, C. A., \& Soeiro, T. M. (2016). Contradição institucional e o Balanced scorecard: Um caso de mudança sem sucesso. Revista Universo Contábil, 12(1), 45-65. doi:10.4270/ruc.2016103

Williamson, O. (1971). The vertical integration of production: Market failure considerations. The American Economic Review, 61(2), 112-123.

Zucker, L. G. (1977). The role of institutionalization in cultural persistence. American Sociological Review, 42(5), 726-743. 